\title{
Language Teaching in Cross-Disciplinary Contexts
}

\author{
Phuong Nguyen Hoang ${ }^{1 *}$ \\ ${ }^{\mathrm{T}}$ University of Social Sciences and Humanities, VNU - HCMC, Vietnam \\ *Corresponding Author \\ Phuong Nguyen Hoang
}

\section{Article History}

Received: 24.02.2021

Accepted: 07.04.2021

Published: 17.04.2021

\begin{abstract}
Cross-disciplinarity is more and more important because of the wide specialization demanded by job markets. Separate disciplines are demanded with increasing urgency to integrate their concepts and methods in teaching and research. Only through the intersection of different disciplines can progress and innovation be achieved in specific knowledge areas. It is said that much leading science nowadays progresses not by placing one brick upon the other within a single discipline, but by solving complex problems that cut across many disciplines. Language teaching has to conform to what today's society demands from professional occupations: a cross-disciplinary role with a result-oriented focus. Cognitive science can provide an adequate model for cross-disciplinary investigation because it integrates linguistic, psychological, philosophical, neurological, computer science, anthropological and historical contributions. Within the cognitive paradigm, a linguistic term does not exclusively exist because of its relations with others but also of culturebased and conventionalized background knowledge. We will use and rely on principles and models of cognitive linguistics to apply and handle language teaching in cross-disciplinary contexts.
\end{abstract}

Keywords: Cross-disciplinarity, cognitive, integrate, context, language teaching.

\section{INTRODUCTION}

Cross-disciplinarity should be viewed as an interactive and practical task, an activity to apply to everyday professional practice. There can be many different ways to develop its practice creatively and initiatively. Experiences from practical implementation of cross-disciplinary action in language teaching have been proposed [1]. The importance of cross-disciplinarity is also growing because of the wide specialization demanded by job markets and partly assumed by universities. Dogan and Pahre [2] argue that only through the intersection of different disciplines can progress and innovation be achieved in specific knowledge areas. Leading science nowadays proceeds not by placing one brick upon the other within a single discipline, but by solving complex problems that cut across many disciplines. Unless the universities adapt to this change, they will be pushed back to the margin of science.

\section{Teaching language in cross-disciplinary contexts}

Language teaching has to conform to what today's society demands from professional occupations: a crossdisciplinary role and with a result-oriented focus. General language teaching requires a thorough analysis of various aspects concerning the student's profile. The following factors must be taken into account: social, economic, psychological and occupational ones. Resorting to the university libraries, consulting specific journals or looking at newspaper classified ads can be other strategies that the teacher can follow. Students can also provide information by answering questionnaires, in personal interviews, etc. [3]. The concept of cross-disciplinarity must be considered right at the first stages of language teaching, such as, course design when targets are established and needs are analyzed. And the cognitive theoretical model should be used to study when considerations on cross-disciplinary research are made. Below are some specific applications teaching language in cross-disciplinary contexts.

\section{Teaching vocabulary}

Sweetser argued, "a pervasive and coherently structured system of metaphors underlies our tendency to use vocabulary from the external domain in speaking of the internal domain" [4]. Metaphor is used when a word belonging to one cognitive domain is conceptualized in terms of a different one. Usually, an abstract domain is conceptualized in

Copyright (C) 2021 The Author(s): This is an open-access article distributed under the terms of the Creative Commons Attribution 4.0 International License (CC BY-NC 4.0) which permits unrestricted use, distribution, and reproduction in any medium for noncommercial use provided the original author and source are credited. 
terms of a more familiar, more physical one. That is one of the reasons why metaphor abounds in technical or scientific discourse because of its abstract nature. Many examples of metaphor can be found in technical English. For example, civil engineering structures can undergo "stress" or "strain", "torsion", "tension" and "fatigue". They can also "age", "fracture", "be dynamic" and "have degrees of freedom". Concrete can be "cured" and can also "bleed", "sweat" or "weep". The underlying mapping in these examples consists of conceptualizing these elements as if they were living things. Lakoff [5] said: "the experiential basis of metaphor". Their function is making technical descriptions more accessible by establishing parallel correspondences between two different conceptual domains: an abstract one on the behavior, functions or reactions of engineering structures is conceptualized using physical terms on body behavior, functions or reactions. The latter domain activates physical and concrete mappings which are more immediate to our experience (figure 1).

\begin{tabular}{|c|c|c|c|}
\hline Mapping & $\begin{array}{ll}\text { Source Domain } & \text { Target Domain } \\
\text { BODY } \longrightarrow & \text { ENGINEERING } \\
\text { STRUCTURES }\end{array}$ & Mapping & $\begin{array}{c}\text { Source Domain } \\
\text { BODY }\end{array} \longrightarrow \begin{array}{c}\text { Target Domain } \\
\text { CONCRETE }\end{array}$ \\
\hline & CORRESPONDENCES & & CORRESPONDENCES \\
\hline $\begin{array}{l}\text { Engineering } \\
\text { structures } \\
\text { undergo } \\
\text { physical } \\
\text { damage }\end{array}$ & $\begin{array}{l}\text { stress } \\
\text { strain } \\
\text { fatigue } \\
\text { torsion } \\
\text { fracture } \\
\text { collapse }\end{array}$ & $\begin{array}{c}\text { Concrete } \\
\text { has } \\
\text { physical } \\
\text { reactions }\end{array}$ & $\begin{array}{l}\text { bleed } \\
\text { sweat } \\
\text { weep }\end{array}$ \\
\hline
\end{tabular}

Fig-1: Examples of metaphorical mapping in technical language

What are the implications of highlighting the use of metaphor in technical terminology? First, it could make easier the teaching of vocabulary. The metaphor mechanism provides a certain unity to the otherwise isolated terms, directly fostering their retention in long-term memory. Secondly, the study of sub-technical vocabulary can be better appreciated if structured in terms of meaning extensions or meaning chains.

\section{Teaching prepositions}

Traditional linguistic approaches treated the multiple meanings associated with prepositions as arbitrary. These approaches also offered imprecise propositional definitions for the prepositions. Traditional pedagogical approaches followed suit and presented the meanings of prepositions as a list of unrelated, vague dictionary-type definitions; the recommended strategy for learning has long been memorization. However, the development of the principled polysemy model [6] clearly demonstrated that by re-envisioning the nature of language and tying the forms it takes to established principles of human cognition and embodied experience, the semantics of prepositions are systematic and motivated. Learning the multiple uses and subtle distinctions between English prepositions is a well-recognized challenge for L2 learners. Brugman [7], Lakoff [8], and Vandeloise [9], Tyler and Evans [10] saw that the many meanings associated with all English prepositions can be accounted for in terms of systematically related meaning networks (polysemy networks). They hypothesized that the Cognitive linguistics-based analyses and their motivated polysemy networks have the potential to provide more precise representations of the meanings of individual prepositions and useful rubrics for learning the multiple meanings associated with each preposition. The key concepts which formed the basis of the analysis of prepositions' meanings are the familiar notions of the communicative nature of language, embodied experience, especially the original spatial nature of prepositions, linguistic units as labels for spatial scenes, varying construals on scenes, and knowledge of real world force dynamics, metaphor and experiential correlation, prototypes and networks and the role of frequency and grammaticalization in meaning extension. To native speakers, each preposition has a different meaning and would be used to convey a different perspective on the scene. However, L2 learners often have to struggle hard to make these distinctions with consistency and confidence. This is probably true for most languages, as attested by Lam's [11] study of English learners learning Russian prepositions such as $3 a, \mu a$, and 6 . The findings from the experiments suggest that Cognitive linguistics provides the tools for re-conceptualizing prepositional meaning in ways that are accessible and useful to L2 learners. Here are some examples.

First, we examine the case of in and out. There is a universal general conceptualization that when we move from an open, broader space outside to an enclosed, narrower space inside, that is moving in; and vice versa, that is moving out. Then, this conceptualization is brought into language. And we have expressions at all levels of language as in the room, go in, get out, in the program, in my opinion, out of stock, etc. This is perfectly true for all disciplines, all cultures.

Second, we examine the case of to, for and at. Here is an exercise for our students to fill in the blanks with appropriate prepositions. 


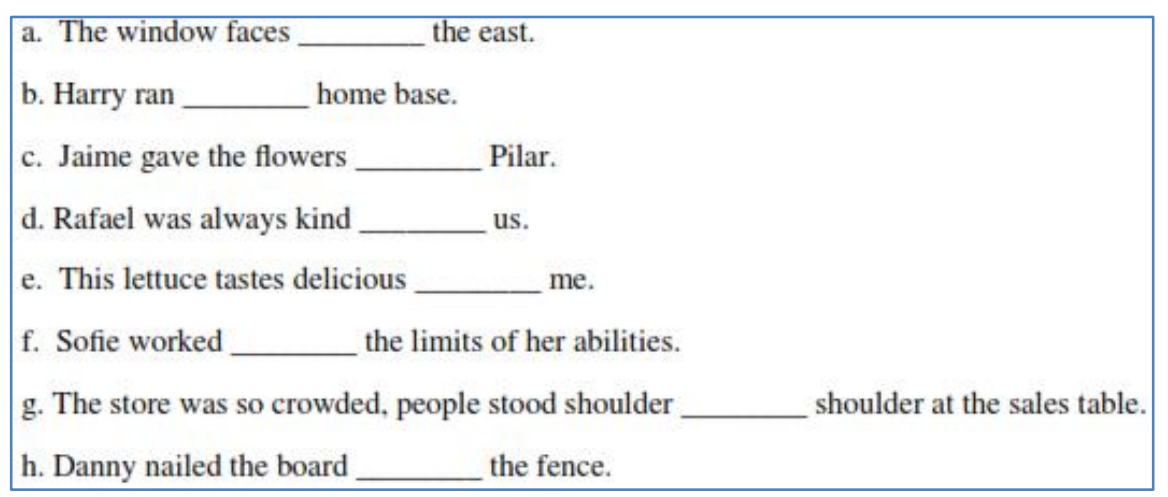

The answer may be a surprise. However, one preposition can be used to fill in all the blanks. That is the preposition to. So, now, what are their different meanings conceptualized in the preposition to? Here is the answer.

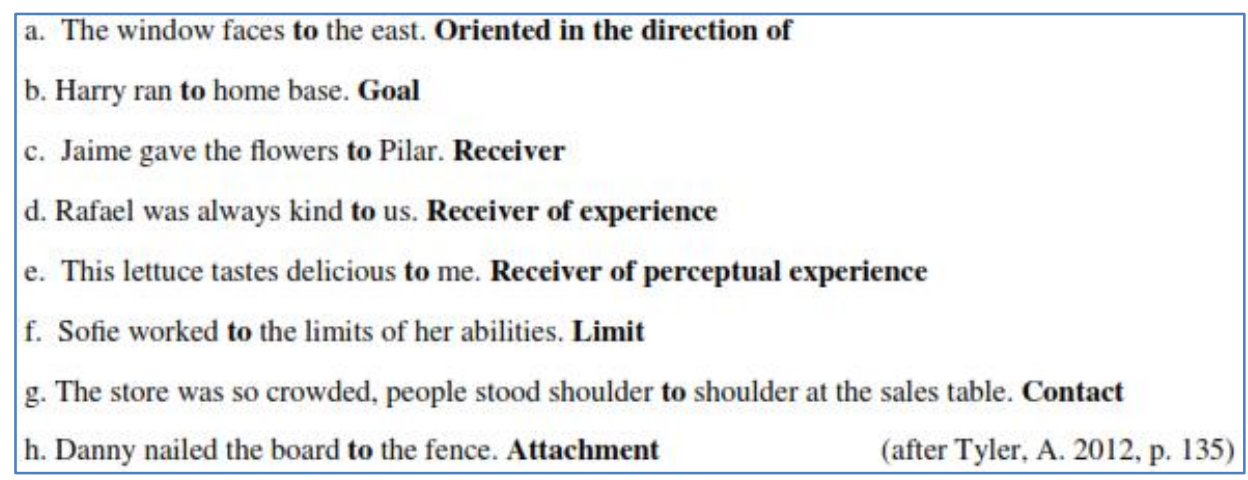

Everything would not be so hard for learners and teachers if learners were provided the meaning map of to before they do the exercise. It would be clearer to understand, to explain, easier to do and to be memorized.

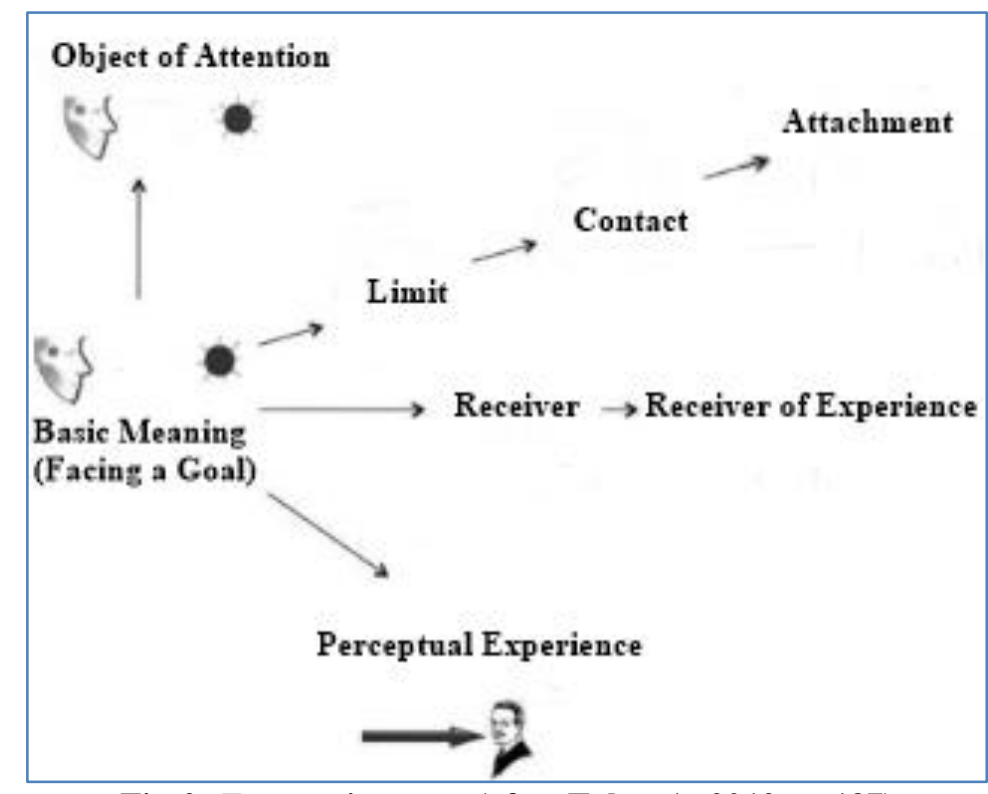

Fig-2: To meaning map (after Tyler, A. 2012, p. 137)

\section{Teaching clauses}

A clause is a meaningful combination of words that contains a subject and a verb, can express a complete thought. In our understanding of the structure of language, traditional approaches represent the syntactic patterns as slots to be filled with grammatical word types:

\begin{tabular}{|c|c|c|c|}
\hline The wind & blew & the paper & Off the table. \\
\hline subject & verb & object & prep phrase \\
\hline
\end{tabular}


In contrast, a Cognitive linguistics approach represents the same sentence in terms of the participants in a familiar scene:

\begin{tabular}{|c|c|c|c|}
\hline The wind & blew & the paper & off the table. \\
\hline Causer & Caused motion & Undergoer & Path \\
\hline
\end{tabular}

Sentences which seem to present the same propositional content but display different forms, alternating syntactic forms, are treated as separate constructions providing different construals on the scene. Goldberg [12] gave the connections among Construction, Meaning and Form, reflecting scenes that are basic to the human experience, such as "something moving" and "someone transfers something to someone else", very humanly relevant scenes.

Table -1: English Argument Constructions

\begin{tabular}{|c|c|c|}
\hline Construction & Meaning & Form \\
\hline Cause to receive & $\mathrm{X}$ CAUSES Y to RECEIVE $\mathrm{Z}$ & $\begin{array}{l}\text { Sub V Obj Obj2 } \\
\text { Pat faxed Bill the letter. }\end{array}$ \\
\hline Caused motion & $\mathrm{X}$ CAUSES $\mathrm{Y}$ to MOVE $\mathrm{Z}$ & $\begin{array}{l}\text { Sub V Obj Oblique } \\
\text { Pat sneezed the napkin off the } \\
\text { table. }\end{array}$ \\
\hline Resultative & $\mathrm{X}$ CAUSES Y to BECOME Z & $\begin{array}{l}\text { Subj V Obj Xcomp } \\
\text { She kissed him unconscious. }\end{array}$ \\
\hline Intrans. motion & X MOVES Y & $\begin{array}{l}\text { Subj V Oblique } \\
\text { The fly buzzed into the room. }\end{array}$ \\
\hline
\end{tabular}

Through the examples, we can see that teaching learners with what is happening around them, with "humanly scenes" can help them acquire the new language easier despite their disciplines, their cultures, their backgrounds because the constructions are authentic, simple and lively. Learners can get rid of unfamiliar, jejune, vague, notation-like and hard to remember, recall and explain clearly like this way.

\begin{tabular}{|c|c|c|c|}
\hline David & gives & Mary & a cake. \\
\hline Subject & Verb & Object 1 & Object 2 \\
\hline
\end{tabular}

Instead, it will be a lot more vivid with this way of teaching and learning.

\begin{tabular}{|c|c|c|c|}
\hline Someone & to give & Someone & Something \\
\hline David & gives & Mary & a cake. \\
\hline
\end{tabular}

\section{CONCLUSION}

In the context of globalization and global integration today, the development perspective focuses on multisectoral, inter-disciplinary and cross-disciplinary development. With the current scientific development, all researches must have an inter-disciplinary and cross-disciplinary nature. Education today must promote these factors because of the wide specialization demanded by job markets. The training objectives need to be changed in the direction of promoting creativity, developing personal ability, being inter-disciplinary and cross-disciplinary as much as possible. The thinking of teaching and learning needs to be changed in a new way so that learners can both acquire knowledge and apply it creatively in practice. There should be a combination of traditional methods (presentation, conversation, practice, etc.) with new methods (problem solving, case study, action-oriented teaching, etc.) towards high practicality, maximum time savings but the most effective and practical application. Therefore, we should always try our best to research and explore the optimal methods and approaches to teach language so that learners can learn the best and fastest, meeting the highest requirement of learners' purpose of learning.

\section{REFERENCES}

1. Rigol, V. R., \& Roldán, R. A. (1992). Dos casos prácticos de colaboración interdisciplinar para alumnos aventajados de inglés. Actas de las Jornadas: La innova-ción emergente como medio de mejora de la calidad de enseñanza en la ingeniería, 58-70. Madrid: ICE.

2. Dogan, M., \& Pahre R. (1990). Creative Marginality: Innovation at the Intersection of Social Sciences. 
Boulder \& Oxford: Westview Press.

3. Edwards, P. (1996). The LSP teacher: to be or not to be? That is the question. Ibérica 0: 9-25.

4. Sweetser, E. (1990). From etymology to pragmatics: Metaphorical and cultural aspects of semantic structure. Cambridge, UK: Cambridge University Press.

5. Lakoff, G. (1992). The Contemporary Theory of Metaphor. In A. Ortony (ed.) Metaphor and Thought (2nd edition). Cambridge: Cambridge University Press.

6. Tyler, A., \& Evans, V. (2003). The semantics of English prepositions: Spatial scenes, embodied meaning and cognition. Cambridge, UK: Cambridge University Press.

7. Brugman, C. (1988). The story of over: Polysemy, semantics and the structure of the lexicon. New York: Garland Press.

8. Lakoff, G. (1987). Women, fire, and dangerous things: What categories reveal about the mind. Chicago, IL: University of Chicago Press.

9. Vandeloise, C. (1994). Methodology and analyses of the preposition in. Cognitive Linguistics, 5(2), $157-184$.

10. Tyler, A. (2012). Cognitive linguistics and second language learning: Theoretical basics and experimental evidence. New York: NY: Rouledge.

11. Lam, Y. (2009). Applying cognitive linguistics to the teaching of the Spanish prepositions por and para. Language Awareness, 18(1), 2-18.

12. Goldberg, A. E. (1995). Constructions: A construction grammar approach to argument structure. Chicago. IL: Chicago University Press.

CITATION: Phuong Nguyen Hoang (2021). Language Teaching in Cross-Disciplinary Contexts. South Asian Res J Art Lang Lit, 3(2): 18-22. 